\title{
Perioperative stroke: pathophysiology and management
}

\author{
Sang-Bae Ko \\ Department of Neurology, Seoul National University Hospital, Seoul, Korea
}

\begin{abstract}
Although perioperative stroke is uncommon during low-risk non-vascular surgery, if it occurs, it can negatively impact recovery from the surgery and functional outcome. Based on the Society for Neuroscience in Anesthesiology and Critical Care Consensus Statement, perioperative stroke includes intraoperative stroke, as well as postoperative stroke developing within 30 days after surgery. Factors related to perioperative stroke include age, sex, a history of stroke or transient ischemic attack, cardiac surgery (aortic surgery, mitral valve surgery, or coronary artery bypass graft surgery), and neurosurgery (external carotid-internal carotid bypass surgery, carotid endarterectomy, or aneurysm clipping). Concomitant carotid and cardiac surgery may further increase the risk of perioperative stroke. Preventive strategies should be individualized based on patient factors, including cerebrovascular reserve capacity and the time interval since the previous stroke.
\end{abstract}

Keywords: Embolism; Hemorrhage; Ischemia; Perioperative; Stroke; Surgery.

\section{Introduction}

Perioperative stroke is the most unwanted complication for patients, as well as for surgeons and anesthesiologists [1]. The reported risk of perioperative stroke varies with the type of surgery. Its incidence is generally not high (approximate $0.1-1.9 \%$ ) in non-cardiac, non-neurologic, and non-major surgery [2]. However, it may occur in up to $10 \%$ of patients undergoing high-risk cardiac or brain surgery [1]. Perioperative stroke can develop intraoperatively or post-operatively after recovery from anesthesia. Identifying perioperative stroke is sometimes chal-

Corresponding author: Sang-Bae Ko, M.D., Ph.D.

Department of Neurology, Seoul National University Hospital, 101, Daehak-ro, Jongno-gu, Seoul 03080, Korea

Tel: 82-2-2072-2278, Fax: 82-2-3672-7553

Email: sangbai1378@gmail.com

ORCID: https://orcid.org/0000-0002-9429-9597

Received: November 5, 2017.

Accepted: November 19, 2017.

Korean J Anesthesiol 2018 February 71(1): 3-11

https://doi.org/10.4097/kjae.2018.71.1.3 lenging. Difficulty in awakening from anesthesia may be the first clue to a clinical suspicion of perioperative stroke. Lingering anesthesia may delay diagnosis of neurologic deficits in patients. Therefore, it is challenging to ascertain the time of onset, which may limit the use of thrombolytic therapy or endovascular thrombectomy (EVT), consequently leading to a poor neurological outcome. Perioperative stroke has a significant negative impact on recovery from surgery. Patients with perioperative stroke are less likely to have a good functional outcome and have an eight-fold higher mortality compared with those without perioperative stroke [3].

According to the Main Surgery Statistical Yearbook for 2015, published by Korean Health Insurance Assessment and Management, the numbers of major surgery in Korea increased from $1,688,516$ to $1,721,390$ (i.e., by $2 \%$ ) over the recent five years. This trend is expected to continue in the coming decades [4]. Given that the age of the patient is a risk factor for perioperative stroke, the increasing percentage of the elderly population will probably lead to a higher incidence of perioperative stroke in Korea, soon.

Therefore, the prevention, early diagnosis, and proper management of perioperative stroke is very important. The current

(c) This is an open-access article distributed under the terms of the Creative Commons Attribution Non-Commercial License (http://creativecommons.org/ licenses/by-nc/4.0/), which permits unrestricted non-commercial use, distribution, and reproduction in any medium, provided the original work is properly cited. 
study will focus on the risk factors of perioperative stroke and the challenges in managing it.

\section{Definition and Pathophysiology}

The Society for Neuroscience in Anesthesiology and Critical Care Consensus Statement defined a perioperative stroke as a brain infarction of ischemic or hemorrhagic etiology, which occurs during surgery or within 30 days after surgery, including the development of stroke after recovering from anesthesia [5]. The peak timing of perioperative stroke may vary depending on the type of surgical procedure. One study, based on the results of patients who underwent general surgery, reported that true intraoperative stroke was very rare and that most perioperative strokes occurred, on average, seven days after surgery [6]. However, intraoperative events may be more important for patients undergoing high-risk operations, such as cardiovascular surgery or neurosurgery. A prospective imaging study on patients who underwent coronary artery bypass graft (CABG) surgery demonstrated that a new brain infarction was detected in $27.6 \%$ of patients on day 3 after surgery. However, most were small silent cortical lesions, and clinically evident stroke was only seen in $3.1 \%$ of patients [7].

Although perioperative strokes incorporate both ischemic and hemorrhagic strokes, the majority are ischemic in origin. In one study, among the 388 patients who underwent CABG surgery, embolic strokes were noted in $62.1 \%$ of patients, followed by strokes due to unknown etiology $(13.9 \%)$ and multiple etiologies (10.1\%), and hypoperfusion (8.8\%), lacunar (3.1\%), thrombotic (1.0\%), and hemorrhagic (1\%) strokes [8]. Putative sources of embolism from the heart can occur due to pre-existing or new-onset atrial fibrillation, vulnerable high-risk aortic arch atheroma, or atherosclerotic large arteries due to manipulation during surgical procedures [9]. Given that most cases are embolic strokes, cerebral lesions usually show a pattern of scattered lesions, in multiple vascular territories, which vary in size (Fig. 1). Fat or air embolism can also sometimes be a source of perioperative stroke in specific clinical settings (Fig. 2).
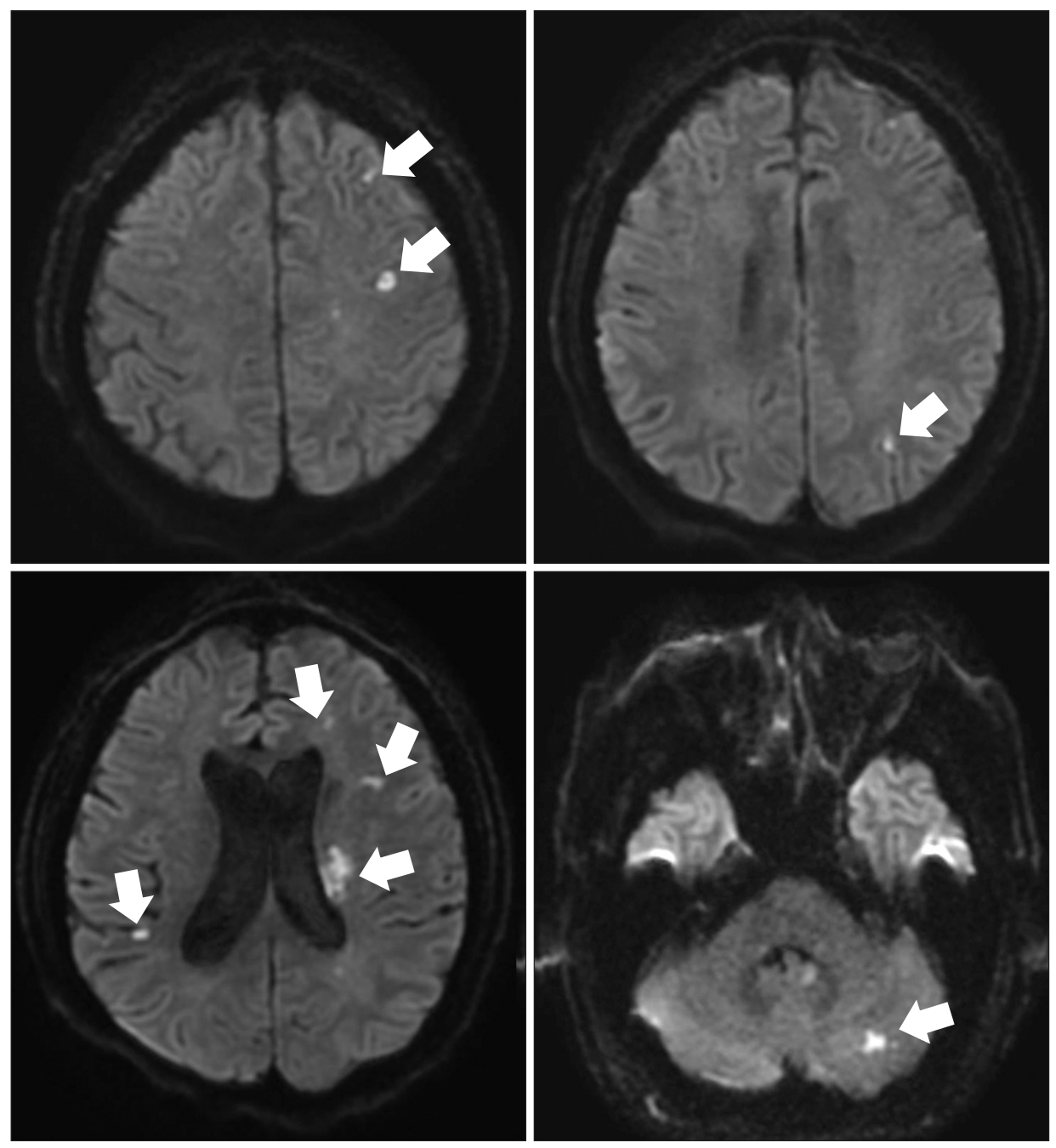

Fig. 1. Brain magnetic resonance imaging of a patient with perioperative stroke. The patient underwent mitral valve replacement surgery, and right side hemiparesis was found upon arousal from anesthesia. Brain magnetic resonance imaging using diffusionweighted imaging (DWI) revealed multiple high signal intensities in the bilateral anterior and posterior circulation territories (arrows). The ischemic lesions on DWI suggested multiple embolisms as the underlying mechanism. 

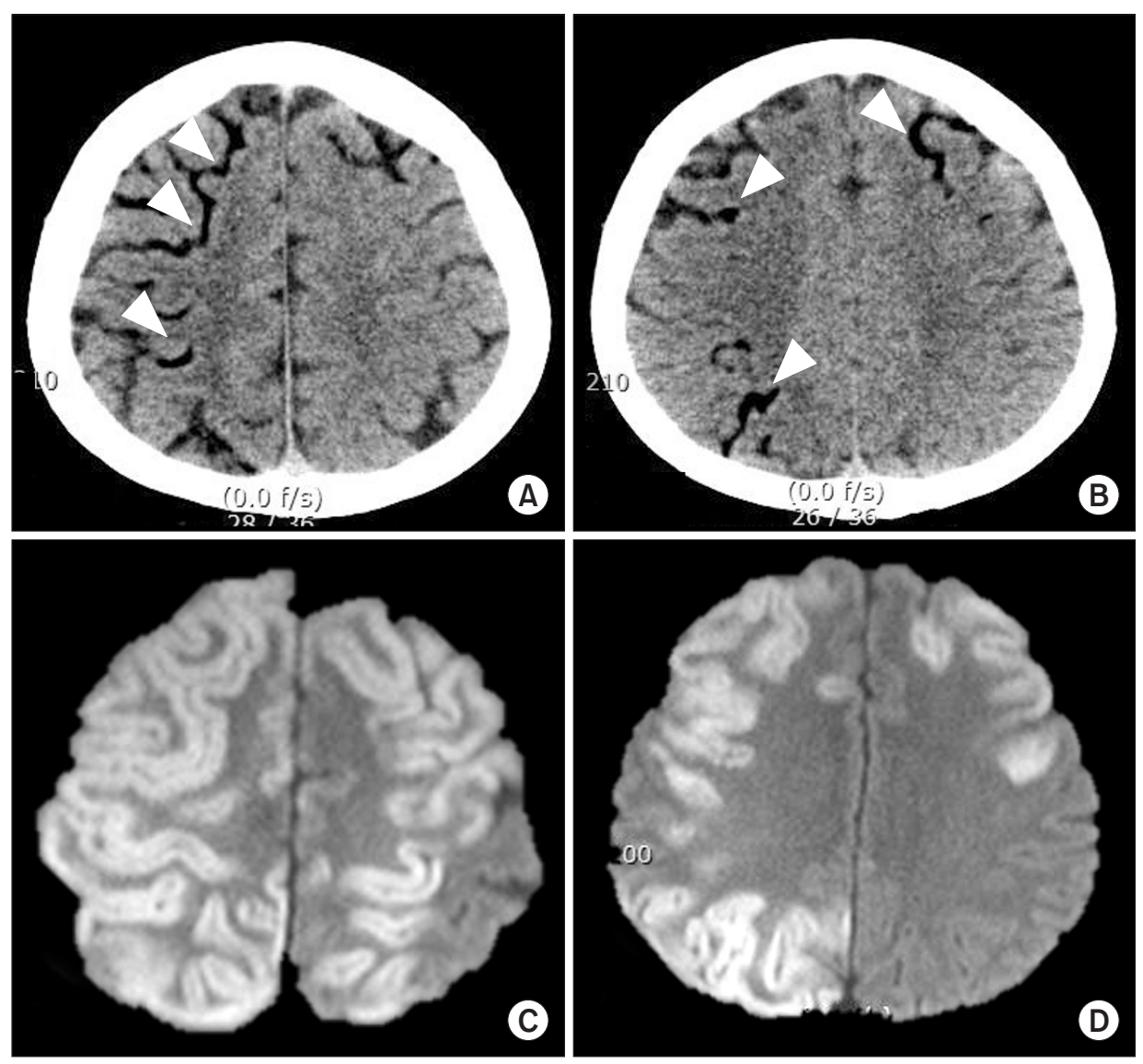

Fig. 2. Perioperative stroke due to air embolism. A 57-year-old male patient underwent emergent aortic arch replacement surgery due to type 1 aortic dissection. During the procedure, a large amount of air was introduced via cardiopulmonary bypass pump due to a problem in the circuit. Immediately after the surgery, there were low attenuated lesions in the cortical pial vessels on computed tomography (A and B, arrowheads). Follow up diffusion-weighted imaging on day 2 revealed high signal intensity lesions in the corresponding cerebral cortex (C and D).

As described earlier, low flow or hypoperfusion infarctions seem to be less frequent than considered. Patients with preexisting severe large artery steno-occlusion may have ischemic lesions in the border zone. However, in 35 patients with severe internal carotid artery (ICA) stenosis, only 3\% (1/35) of patients had stroke lesions in the border zone alone. In addition to the border zones, the majority of patients also had lesions in the cortical pial artery territories, which suggested that the main mechanism of ischemic stroke in severe ICA stenosis was embolic in origin, rather than due to hypoperfusion [10]. Moreover, in a retrospective study of 128 patients who underwent carotid endarterectomy (CEA), although all patients had contralateral carotid occlusions, only $1.6 \%$ of patients had permanent neurological deficit [11]. Taken together, these results demonstrated that hypoperfusion or low-flow infarction may not be a major stroke mechanism in perioperative stroke.

Thrombosis is augmented after surgical procedures partly due to systemic inflammation or activation of the normal hemostatic pathway [12]. Moreover, this mechanism may be more intense in patients who stopped using anti-thrombotic agents to prepare for surgery [13]. Therefore, thrombosis, whether it is a rebound phenomenon or not, might play an additional role in patients with a history of stroke.
The proportion of intracerebral hemorrhage (ICH) in perioperative stroke is as low as $1 \%$. The suggested mechanisms of hemorrhagic stroke are as follows: 1) a sudden surge of blood pressure up to the level of the autoregulatory breakthrough zone, or 2) coagulopathy, medications like an antiplatelet agent, or anticoagulation. Given that most anesthetic agents induce hypotension, they are mechanistically less likely to provoke $\mathrm{ICH}$ while under anesthesia. However, perioperative ICH can develop in certain clinical settings that are closely linked to a sudden surge of cerebral perfusion. Elevated blood pressure after revascularization procedures, such as CEA or carotid artery stenting (CAS), often lead to cerebral hyperperfusion syndrome (CHS) and may result in the development of ICH. CHS is a rare phenomenon but may develop in patients with diminished cerebrovascular reserve, especially when postoperative hypertension persists for longer than several hours [14]. In patients with a limited cerebrovascular reserve capacity, compensatory vasodilatation already exists in the affected vascular territories. Therefore, when a sudden surge of blood pressure occurs after revascularization procedures, cerebral hyperperfusion may consequently lead to the development of ICH. In patients with orthotropic heart transplantation, the risk of hemorrhagic stroke is approximately $2.5 \%$, which is slightly higher than other surgical 
procedures [15]. The location of ICH is mostly located in deeper structures (i.e., basal ganglia, thalamus, pons, and cerebellum) than in the cerebral lobes [16]. ICH pathogenesis in patients with transplantation is probably caused by anticoagulation, a high pressure of the cardiopulmonary bypass (CPB), uncontrolled blood pressure, or hyperperfusion $[17,18]$. Moreover, in the subacute phase after transplantation, the use of calcineurin inhibitors (tacrolimus or cyclosporine) for immune suppression may lead to posterior reversible encephalopathy syndrome, which may lead to the development of ICH in the occipital lobes [19].

\section{Risk Factors}

Risk factors for perioperative stroke include conventional vascular risk factors (i.e., age, sex, or a history of stroke or transient ischemic attack), the type of surgery (i.e., cardiovascular surgery or neurosurgery), or specific intraoperative events. Among patients who underwent mitral valve surgery, the factors associated with perioperative stroke were as follows: age, sex, emergency surgery, arrhythmias, hypertension, renal failure, coagulopathy, neurological disorders, weight loss, anemia, postoperative cardiac arrest, and myocardial infarction [20]. These risk factors can be categorized into modifiable or non-modifiable factors.

\section{Non-modifiable risk factors}

\section{Patient factor}

The age of the patient is one important factor for perioperative stroke. Its risk increases by six-fold among octogenarians compared to younger populations $[21,22]$. A prospective imaging cohort study on patients who underwent CABG demonstrated that age was an independent factor (odds ratio [OR], 1.09; 95\% CI, 1.03-1.15) for new brain lesion after surgery [7]. Even in non-cardiac and non-vascular surgery, age was recognized as an important factor. A total of 371,641 surgeries, over four years, were analyzed in a study using the Nationwide Inpatient Sample (NIS) database from the United States. An old age (per 10 years) had higher odds (OR, 1.43; 95\% CI, 1.35-1.51) for perioperative stroke [2]. Given that the average age of patients undergoing surgical procedures will increase, the incidence of perioperative stroke is likely to increase in the future.

Being female has also been recognized as a risk factor for perioperative stroke in both cardiovascular and non-cardiovascular surgeries $[2,23]$. Although the reason for sex differences in perioperative stroke is not clearly understood, elderly female patients have more rapid progression of atherosclerosis after menopause $[2,24,25]$. In addition, patients with a history of stroke or transient ischemic attack have an elevated risk for peri- operative stroke [26].

A migraine is the most common neurological disorder. A growing body of evidence suggests that there is a strong association between a migraine and ischemic stroke, with a recent study reporting that a migraine might be a risk factor for perioperative stroke [27]. One report, based on hospital-based registry data (124,558 surgical patients; mean age 52.6 years; $54.5 \%$ women), showed that the rate of ischemic stroke over 30 days in this population was $0.6 \%$. Among them, patients with a history of a migraine with aura had a higher OR for perioperative ischemic stroke (OR, 2.61; 95\% CI, 1.59-4.29) compared to those without a history of a migraine.

\section{Types of surgery}

Cardiac surgery: The risk of developing a perioperative stroke is higher with cardiac surgery than with non-vascular surgery. Despite recent surgical technique improvements, perioperative stroke risk is still high in cardiovascular surgeries. The reported risk of perioperative stroke is $1.2 \%$ for CABG, $1.5 \%$ for aortic valve replacement, $2.1 \%$ for mitral valve replacement, and $6.6 \%$ for proximal aorta replacement surgery [28-30]. The higher risk of cerebral embolism could probably be attributed to surgical techniques including the manipulation of the aorta, cannulation, or cross-clamping or side clamping of the aorta [31]. In addition, many studies demonstrated a link between aortic atherosclerosis and cerebral embolism across cardiac surgeries $[29,32,33]$. Taken together, this suggests that intraoperative cerebral embolism may originate from the atherosclerotic aorta due to the manipulation of the aorta, such as during CPB insertion. Therefore, when CPB insertion or aortic manipulation is anticipated, several techniques are used to screen the aortic atheroma, including manual palpation, transesophageal ultrasound, or epiaortic ultrasound, which has greater sensitivity [31]. If a severe aortic atheroma is present, alternate bypass cannulation sites should be chosen. When planning for CABG, off-pump CABG could be a theoretical alternative option to reduce aortic embolism. However, randomized trials comparing the outcome between off-pump and on-pump CABG showed that the risk of immediate perioperative stroke or stroke up to five years were not different [34-37]. Commercial devices such as Embol-X intra-aortic filtration system or CardioGard embolic protection cannula also provides more direct protection from cerebral embolization $[31,38]$.

Based on the database of the Society of Thoracic Surgeons Adult Cardiac Surgery in the United States, concomitant replacement of the supracoronary ascending aorta and aortic arch has the highest risk of stroke (11\%), compared to the ascending aorta alone (6.9\%), aorta root plus arch (6.3\%), and aortic root only (3.9\%). However, this data included results from elective as well as emergent operations. Although further analysis of elec- 
tive operation data demonstrated that the risk of perioperative stroke was halved (i.e., 5.3\%, 3.2\%, 3.4\%, and 2.2\%, respectively), concomitant surgery still had the highest risk for perioperative stroke [30].

Compared to aortic valve surgery, mitral valve surgery has a higher stroke risk. A recent meta-analysis showed that the risk of perioperative stroke within 30 days of surgery was $1.62 \%$ in mitral valve surgery [39]. When concomitant mitral valve replacement and $\mathrm{CABG}$ was performed, the risk increased by $2.05 \%$. The risk was even higher with cases of dual valve replacement (aortic and mitral valve). Moreover, patients with cardiac surgery had a high risk of cardiac arrhythmia, particularly atrial fibrillation, which is a well-known risk factor for embolic stroke. Therefore, when anticoagulation is not used, due to surgical bleeding control during the immediate postoperative period, the presence of atrial fibrillation may cause a postoperative ischemic stroke.

When thoraco-abdominal aortic aneurysm surgery is planned, there is a small but noticeable risk of spinal cord ischemia and infarction (SCI). Population-based cohort series demonstrated that a ruptured aneurysm or aortic dissection repair (either surgically or endovascularly) was associated with a $0.74 \%$ risk of SCI. In cases with an unruptured aortic aneurysm, the risk of SCI was approximately 1 in 600 [40]. Risk factors for SCI include a long duration of aorta clamping, direct thrombotic occlusion of the anterior spinal artery or artery of Adamkiewicz, and global hypoperfusion of the spinal cord.

CABG is a surgical revascularization procedure for unstable angina and myocardial infarction. Therefore, patients undergoing CABG surgery have a lot of vascular and atherosclerotic risk factors including old age, previous stroke, diabetes, hypertension, peripheral artery disease, and renal failure [41]. Given that carotid artery stenosis develops due to atherosclerosis, CABG candidates have a high likelihood of having concomitant carotid stenosis. Ischemic stroke after CABG surgery has a definite negative effect on functional outcome and recovery [42]. The existence of severe carotid stenosis could be a burden for surgeons and anesthesiologists. When patients have concomitant carotid stenosis and unstable coronary disease, several treatment options can be considered as follows: 1) combined CABG and CEA, 2) Staged CEA, followed by CABG, 3) Staged CABG, followed by CEA, 4) Staged CAS, followed by CABG, or 5) CEA with off-pump CABG [43]. However, this strategy should be individualized based on the state of carotid disease (asymptomatic or symptomatic) and urgency of coronary disease (stable angina or unstable angina). A study on the NIS database showed that staged CABG and CEA was associated with approximately a 2.9-9.4\% risk of perioperative stroke [44]. However, randomized trials are required to validate this finding.

Online access in http://ekja.org
Neurosurgery: Candidates for CEA usually have symptomatic high grade (greater than $60-70 \%$ ) carotid stenosis. During the several decades after the publication of the North American Carotid Endarterectomy Trial (NASCET) and the Asymptomatic Carotid Atherosclerosis Study (ACAS), the perioperative complication rate significantly decreased [45]. The NASCET trial reported a 30-day perioperative stroke risk of 5.5\% in 1991 [46], while the recent CREST trial, published in 2010, showed that the rate of any periprocedural stroke was $2.3 \%$ in the CEA group and that the stroke event was mostly minor in severity [47]. Real world registry-based analysis showed that the 30-day perioperative stroke risk after CEA was $4.1 \%$, which was higher in patients who previously presented with stroke, compared to those who had ocular or hemispheric TIA (1.4\% or $2.5 \%$, respectively) [45]. Moreover, contralateral stroke rarely occurred in patients with CEA. The 30-day contralateral perioperative stroke rate was $0.5 \%$; urgent CEA and a long operation duration were related to contralateral ischemic events [48].

In Moyamoya disease, direct extracranial-intracranial (ECIC) bypass surgery is a standard treatment option for revascularization. However, it is still unclear whether EC-IC bypass surgery plays a role in atherosclerotic ICA occlusion, since this association between the two could not be validated in The Carotid Occlusion Surgery Study (COSS). In the surgical bypass group, the 30-day ipsilateral perioperative stroke risk was $14.4 \%$, which was higher than in the medical treatment group [49]. However, a secondary analysis showed that only $21 \%$ of those strokes were presumably related to problems due to EC-IC anastomosis [50]. Based on this, we can assume that the perioperative stroke risk with EC-IC bypass surgery is significantly high compared to other surgical procedures.

Clipping of intracranial aneurysm also poses a high risk for the development of perioperative stroke. Using the NIS database, a study reported that the postoperative stroke rate was as high as $6.7 \%$, while the ICH rate was $2.38 \%$ [51]. It must be noted, however, that these rates refer to any stroke or ICH during hospitalization, rather than to the 30-day perioperative stroke. Therefore, the true perioperative stroke risk may be slightly lower than this. However, although the direct comparison is limited, it is possible that a significant portion of patients with aneurysm clipping may experience an ischemic or hemorrhagic stroke.

Non-cardiac and non-neurologic surgery: As described earlier, perioperative stroke risk in patients with general surgery is very low. However, vascular, thoracic, or transplantation surgeries post a higher risk among general surgeries [52]. Recent improvements in surgical techniques have significantly decreased the mortality rate and myocardial infarction rate. However, the risk of perioperative stroke increased from $0.52 \%$ (in 2004) to $0.77 \%$ (in 2013) among patients who underwent general surgery [52]. 


\section{Modifiable risk factors}

\section{Carotid stenosis}

Although still under debate, severe carotid stenosis is a possible independent risk factor for perioperative stroke [53]. Severe carotid stenosis may limit ipsilateral cerebral perfusion and may be a source of cerebral embolism in patients undergoing surgery, which is a reason to treat carotid stenosis before surgical procedures. However, another study showed conflicting results. Among patients with carotid stenosis indicated for open heart surgery, the risk of perioperative stroke was lower if carotid stenosis was left untreated, compared to those who underwent concomitant cardiac and carotid surgery [54]. This poses questions about the treatment of concomitant carotid stenosis in patients undergoing surgical procedures.

When patients are in the preparation for high-risk cardiac surgery, such as CABG, or aortic arch or valve surgery, screening for carotid artery stenosis is usually performed. Patients with severe carotid stenosis are highly likely to have concomitant aortic atheroma, which is associated with an increased risk of perioperative stroke. However, even with severe carotid stenosis, the timing and requirement for carotid revascularization before surgery should be individualized, based on the urgency of surgery, vascular reserve in the hemisphere of the stenotic carotid artery, and presence or absence of symptoms related to carotid stenosis. Moreover, concomitant carotid revascularization surgery and the originally planned surgery may increase the risk of perioperative stroke.

\section{Timing of surgery after previous stroke}

A history of stroke is directly linked to the risk of perioperative stroke. However, it is unclear how long after the index stroke a surgery should be performed to minimize the perioperative stroke risk [3]. A nationwide retrospective study aimed to answer this question and reported that, regardless of the timing between stroke and surgery, a history of stroke increased the odds of 30-day mortality by 1.8 -fold in patients with non-cardiac surgery. Interestingly, the association between a history of stroke and major adverse event disappeared after nine months [55]. Therefore, it may be reasonable to delay elective non-neurological non-cardiac surgery. This decision should be individualized based on the risk of delaying surgery (the urgency of surgery) and the risk of perioperative stroke of the patients (status of perfusion and autoregulation). Expert opinion suggested that delaying surgery by at least one month after the index stroke would allow restoration of cerebral autoregulation, which in turn would decrease the risk of developing perioperative stroke.

\section{Intraoperative hypotension}

Most anesthetic agents may induce hypotension. Intraopera- tive hypotension is a risk factor for perioperative stroke, especially when patients have significant large vessel stenosis [56]. A sudden drop in blood pressure may decrease the cerebral perfusion pressure below the limit of the autoregulation zone, which may lead to brain ischemia and perioperative stroke. This is particularly important for patients with recent ischemic stroke.

\section{Intraoperative hypoxia}

Intraoperative poor systemic oxygenation might be a risk factor for perioperative stroke in patients with CPB [57]. A single center study over three years demonstrated that lower nadir $\mathrm{PaO}_{2}$ values were associated with postoperative stroke, with the estimated odds of stroke increasing over $20 \%$ (OR, 1.23; $95 \%$ CI, 1.07-1.41) per $10 \mathrm{mmHg}$ lower nadir $\mathrm{PaO}_{2}$ [57]. Therefore, when a low intraoperative oxygen level is identified, it should be properly corrected.

\section{Prevention and Treatment}

\section{Perioperative use of beta blocker}

Perioperative use of beta blockers might be beneficial in reducing heart rate and sympathetic activity, which in turn might lower the risk of cardiac arrhythmia, myocardial infarction, and possibly stroke. A recent meta-analysis analyzed the effect of beta blockers on cardiovascular outcome in patients who underwent vascular and endovascular surgery [58]. Among the 32,602 patients from three randomized trials, five retrospective, and three prospective cohorts studies, perioperative beta blockers did not reduce stroke (OR, 2.45; 95\% CI, 0.89-6.75, P=0.08). The effect of extended-release metoprolol on cardiovascular outcome was assessed, in patients undergoing non-cardiac surgery, in the PeriOperative ISchemic Evaluation (POISE) trial [59]. Although patients in the metoprolol group had fewer cardiovascular deaths or myocardial infarctions, they had a significant increase (2.2-fold) in stroke from day 1. Therefore, special caution should be executed, in terms of perioperative stroke, when patients are exposed to extended-release metoprolol in a preoperative setting.

\section{Intravenous thrombolysis}

A history of major surgery within 14 days is an exclusion criterion for the administration of tissue-type plasminogen activator (tPA) because of the risk of surgical site bleeding [60]. Therefore, even with clear onset symptoms, it is challenging to use intravenous tPA in patients with perioperative stroke. A recent retrospective study compared the effectiveness of off-label use of tPA in patients with perioperative stroke [61]. Among the 134 patients treated with $\mathrm{tPA}, 37 \%$ had recent surgery within 10 
days, and $64 \%$ had major surgery. After treatment with IV tPA, $7 \%$ of patients had surgical site bleeding, which was serious in $3 \%$ of patients, but there were no fatalities. One fatal bleeding occurred remotely from the surgical site. Recent surgery (within 10 days) had higher odds for surgical site hemorrhage (OR 10.7) compared to remote surgery, after treatment with IV tPA. Although the intracranial hemorrhage rate was $9.7 \%$, all cases were asymptomatic and not severe. These results indicated that the administration of IV tPA was associated with a high risk of surgical site bleeding. Thus, the use of tPA should be individualized based on the risk and benefit of the treatment in specific patients.

\section{Intra-arterial mechanical thrombectomy}

Multiple randomized clinical trials demonstrated that EVT in patients with anterior circulation ischemia with large vessel occlusion (mainly of the intracranial ICA, middle cerebral artery [MCA] main trunk, or the M2 major branch of the MCA) led to effective recanalization and a better clinical outcome, without an additional risk of hemorrhagic complication [62]. Thus, EVT is considered as a treatment option for perioperative stroke. Another study focused on the procedural success rate of EVT in patients with perioperative stroke [63]. Patients with periopera- tive stroke had similar rates of recanalization and major procedural complication, compared to patients without perioperative stroke. However, the functional outcome and mortality rate was significantly worse in patients with perioperative stroke.

\section{Intravenous infusion of unfractionated heparin}

The use of intravenous unfractionated heparin is not a standard treatment option, even for cardioembolic stroke. The administration of unfractionated heparin does not lead to better recanalization of occluded vessels [64]. It could also increase complications like symptomatic hemorrhagic transformation or heparin-induced thrombocytopenia. Therefore, the use of intravenous unfractionated heparin has recently been decreased [65]. Given the high risk of bleeding complication, the use of intravenous heparin is not recommended for perioperative stroke.

\section{Conclusion}

The risk of perioperative stroke can vary based on patient risk factors, the type of surgery, or intraoperative hypotension or hypoxia. Thus, special caution is warranted for high-risk patients undergoing cardiovascular or neurological surgery.

\section{References}

1. Selim M. Perioperative stroke. N Engl J Med 2007; 356: 706-13.

2. Bateman BT, Schumacher HC, Wang S, Shaefi S, Berman MF. Perioperative acute ischemic stroke in noncardiac and nonvascular surgery: incidence, risk factors, and outcomes. Anesthesiology 2009; 110: 231-8.

3. Sanders RD, Jørgensen ME, Mashour GA. Perioperative stroke: a question of timing? Br J Anaesth 2015; 115: 11-3.

4. The main surgery statistical yearbook for 2015. Health Insurance Review and Assessment Service. 2016.

5. Mashour GA, Moore LE, Lele AV, Robicsek SA, Gelb AW. Perioperative care of patients at high risk for stroke during or after non-cardiac, non-neurologic surgery: consensus statement from the Society for Neuroscience in Anesthesiology and Critical Care* J Neurosurg Anesthesiol 2014; 26: 273-85.

6. Kam PC, Calcroft RM. Peri-operative stroke in general surgical patients. Anaesthesia 1997; 52: 879-83.

7. Nah HW, Lee JW, Chung CH, Choo SJ, Kwon SU, Kim JS, et al. New brain infarcts on magnetic resonance imaging after coronary artery bypass graft surgery: lesion patterns, mechanism, and predictors. Ann Neurol 2014; 76: 347-55.

8. Likosky DS, Marrin CA, Caplan LR, Baribeau YR, Morton JR, Weintraub RM, et al. Determination of etiologic mechanisms of strokes secondary to coronary artery bypass graft surgery. Stroke 2003; 34: 2830-4.

9. Blacker DJ, Flemming KD, Link MJ, Brown RD Jr. The preoperative cerebrovascular consultation: common cerebrovascular questions before general or cardiac surgery. Mayo Clin Proc 2004; 79: 223-9.

10. Kang DW, Chu K, Ko SB, Kwon SJ, Yoon BW, Roh JK. Lesion patterns and mechanism of ischemia in internal carotid artery disease: a diffusion-weighted imaging study. Arch Neurol 2002; 59: 1577-82.

11. Whitney EG, Brophy CM, Kahn EM, Whitney DG. Inadequate cerebral perfusion is an unlikely cause of perioperative stroke. Ann Vasc Surg 1997; 11: 109-14.

12. Collins GJ Jr, Barber JA, Zajtchuk R, Vanek D, Malogne LA. The effects of operative stress on the coagulation profile. Am J Surg 1977; 133: 612-6.

13. Vlisides P, Mashour GA. Perioperative stroke. Can J Anaesth 2016; 63: 193-204.

14. van Mook WN, Rennenberg RJ, Schurink GW, van Oostenbrugge RJ, Mess WH, Hofman PA, et al. Cerebral hyperperfusion syndrome. Lancet Neurol 2005; 4: 877-88. 
15. Acampa M, Lazzerini PE, Guideri F, Tassi R, Martini G. Ischemic stroke after heart transplantation. J Stroke 2016; 18: 157-68.

16. Cemillán CA, Alonso-Pulpón L, Burgos-Lázaro R, Millán-Hernández I, del Ser T, Liaño-Martínez H. Neurological complications in a series of 205 orthotopic heart transplant patients. Rev Neurol 2004; 38: 906-12.

17. Belvís R, Martí-Fàbregas J, Cocho D, García-Bargo MD, Franquet E, Agudo R, et al. Cerebrovascular disease as a complication of cardiac transplantation. Cerebrovasc Dis 2005; 19: 267-71.

18. Gottesman RF, Sherman PM, Grega MA, Yousem DM, Borowicz LM Jr, Selnes OA, et al. Watershed strokes after cardiac surgery: diagnosis, etiology, and outcome. Stroke 2006; 37: 2306-11.

19. Loar RW, Patterson MC, O'Leary PW, Driscoll DJ, Johnson JN. Posterior reversible encephalopathy syndrome and hemorrhage associated with tacrolimus in a pediatric heart transplantation recipient. Pediatr Transplant 2013; 17: E67-70.

20. Udesh R, Mehta A, Gleason TG, Wechsler L, Thirumala PD. Perioperative strokes and early outcomes in mitral valve surgery: a nationwide analysis. J Cardiothorac Vasc Anesth 2017; 31: 529-36.

21. Kim J, Gelb AW. Predicting perioperative stroke. J Neurosurg Anesthesiol 1995; 7: 211-5.

22. Gelb AW, Cowie DA. Perioperative stroke prevention. Anesth Analg 2001; 92: 46-53.

23. Hogue CW Jr, Murphy SF, Schechtman KB, Dávila-Román VG. Risk factors for early or delayed stroke after cardiac surgery. Circulation 1999; 100: 642-7.

24. Maas AH, Appelman YE. Gender differences in coronary heart disease. Neth Heart J 2010; 18: 598-602.

25. Flora GC, Baker AB, Loewenson RB, Klassen AC. A comparative study of cerebral atherosclerosis in males and females. Circulation 1968; 38: 859-69.

26. Kikura M, Oikawa F, Yamamoto K, Iwamoto T, Tanaka KA, Sato S, et al. Myocardial infarction and cerebrovascular accident following noncardiac surgery: differences in postoperative temporal distribution and risk factors. J Thromb Haemost 2008; 6: 742-8.

27. Timm FP, Houle TT, Grabitz SD, Lihn AL, Stokholm JB, Eikermann-Haerter K, et al. Migraine and risk of perioperative ischemic stroke and hospital readmission: hospital based registry study. BMJ 2017; 356: 16635.

28. ElBardissi AW, Aranki SF, Sheng S, O’Brien SM, Greenberg CC, Gammie JS. Trends in isolated coronary artery bypass grafting: an analysis of the Society of Thoracic Surgeons adult cardiac surgery database. J Thorac Cardiovasc Surg 2012; 143: 273-81.

29. O’Brien SM, Shahian DM, Filardo G, Ferraris VA, Haan CK, Rich JB, et al. The Society of Thoracic Surgeons 2008 cardiac surgery risk models: part 2--isolated valve surgery. Ann Thorac Surg 2009; 88(1 Suppl): S23-42.

30. Williams JB, Peterson ED, Zhao Y, O’Brien SM, Andersen ND, Miller DC, et al. Contemporary results for proximal aortic replacement in North America. J Am Coll Cardiol 2012; 60: 1156-62.

31. Andersen ND, Hart SA, Devendra GP, Kim ES, Johnston DR, Schroder JN, et al. Atheromatous disease of the aorta and perioperative stroke. J Thorac Cardiovasc Surg 2017 [Epub ahead of print].

32. Filsoufi F, Rahmanian PB, Castillo JG, Bronster D, Adams DH. Incidence, topography, predictors and long-term survival after stroke in patients undergoing coronary artery bypass grafting. Ann Thorac Surg 2008; 85: 862-70.

33. Filsoufi F, Rahmanian PB, Castillo JG, Bronster D, Adams DH. Incidence, imaging analysis, and early and late outcomes of stroke after cardiac valve operation. Am J Cardiol 2008; 101: 1472-8.

34. Filardo G, Hamman BL, da Graca B, Sass DM, Machala NJ, Ismail S, et al. Efficacy and effectiveness of on- versus off-pump coronary artery bypass grafting: a meta-analysis of mortality and survival. J Thorac Cardiovasc Surg 2018; 155: 172-9.

35. Shroyer AL, Hattler B, Wagner TH, Collins JF, Baltz JH, Quin JA, et al. Five-year outcomes after on-pump and off-pump coronary-artery bypass. N Engl J Med 2017; 377: 623-32.

36. Hueb W, Lopes NH, Pereira AC, Hueb AC, Soares PR, Favarato D, et al. Five-year follow-up of a randomized comparison between offpump and on-pump stable multivessel coronary artery bypass grafting. The MASS III Trial. Circulation 2010; 122(11 Suppl): S48-52.

37. Lamy A, Devereaux PJ, Prabhakaran D, Taggart DP, Hu S, Paolasso E, et al. Effects of off-pump and on-pump coronary-artery bypass grafting at 1 year. N Engl J Med 2013; 368: 1179-88.

38. Bolotin G, Huber CH, Shani L, Mohr FW, Carrel TP, Borger MA, et al. Novel emboli protection system during cardiac surgery: a multicenter, randomized, clinical trial. Ann Thorac Surg 2014; 98: 1627-33.

39. Udesh R, Natarajan P, Jeevanantham V, Gleason TG, Badhwar V, Thirumala PD. Perioperative strokes following surgical correction of mitral valves: a systematic review and meta-analysis. Eur Neurol 2017; 78: 63-70.

40. Gialdini G, Parikh NS, Chatterjee A, Lerario MP, Kamel H, Schneider DB, et al. Rates of spinal cord infarction after repair of aortic aneurysm or dissection. Stroke 2017; 48: 2073-7.

41. Mérie C, Køber L, Olsen PS, Andersson C, Jensen JS, Torp-Pedersen C. Risk of stroke after coronary artery bypass grafting: effect of age and comorbidities. Stroke 2012; 43: 38-43.

42. Mehta A, Gleason T, Wechsler L, Winger D, Wang L, Thirumala PD. Perioperative stroke as a predictor of mortality and morbidity in patients undergoing CABG. J Clin Neurosci 2017; 44: 175-9.

43. Poi MJ, Echeverria A, Lin PH. Contemporary management of patients with concomitant coronaryand carotid artery disease. World J Surg 2018; 42: 272-82.

44. Cheng H, Udesh R, Mehta A, Thirumala PD. Perioperative strokes after coronary artery bypass grafting with staged carotid endarterectomy: a nationwide perspective. J Clin Anesth 2017; 39: 25-30. 
45. Pothof AB, Zwanenburg ES, Deery SE, O’Donnell TF, de Borst GJ, Schermerhorn ML. An update on the incidence of perioperative outcomes after carotid endarterectomy, stratified by type of preprocedural neurologic symptom. J Vasc Surg 2017 [Epub ahead of print].

46. North American Symptomatic Carotid Endarterectomy Trial Collaborators, Barnett HJ, Taylor DW, Haynes RB, Sackett DL, Peerless SJ, et al. Beneficial effect of carotid endarterectomy in symptomatic patients with high-grade carotid stenosis. N Engl J Med 1991; 325: 445-53.

47. Brott TG, Hobson RW 2nd, Howard G, Roubin GS, Clark WM, Brooks W, et al. Stenting versus endarterectomy for treatment of carotidartery stenosis. N Engl J Med 2010; 363: 11-23.

48. Clouse WD, Ergul EA, Patel VI, Lancaster RT, LaMuraglia GM, Cambria RP. Characterization of perioperative contralateral stroke after carotid endarterectomy. J Vasc Surg 2017; 66: 1450-6.

49. Powers WJ, Clarke WR, Grubb RL Jr, Videen TO, Adams HP Jr, Derdeyn CP. Extracranial-intracranial bypass surgery for stroke prevention in hemodynamic cerebral ischemia: the carotid occlusion surgery study randomized trial. JAMA 2011; 306: 1983-92.

50. Reynolds MR, Grubb RL Jr, Clarke WR, Powers WJ, Zipfel GJ, Adams HP Jr, et al. Investigating the mechanisms of perioperative ischemic stroke in the carotid occlusion surgery study. J Neurosurg 2013; 119: 988-95.

51. Alshekhlee A, Mehta S, Edgell RC, Vora N, Feen E, Mohammadi A, et al. Hospital mortality and complications of electively clipped or coiled unruptured intracranial aneurysm. Stroke 2010; 41: 1471-6.

52. Smilowitz NR, Gupta N, Ramakrishna H, Guo Y, Berger JS, Bangalore S. Perioperative major adverse cardiovascular and cerebrovascular events associated with noncardiac surgery. JAMA Cardiol 2017; 2: 181-7.

53. Udesh R, Solanki P, Mehta A, Gleason T, Wechsler L, Thirumala PD. Carotid artery stenosis as an independent risk factor for perioperative strokes following mitral valve surgical intervention. J Neurol Sci 2017; 382: 170-84.

54. Castaldo JE, Yacoub HA, Li Y, Kincaid H, Jenny D. Open heart surgery does not increase the incidence of ipsilateral ischemic stroke in patients with asymptomatic severe carotid stenosis. J Stroke Cerebrovasc Dis 2017; 26: 2154-9.

55. Jørgensen ME, Torp-Pedersen C, Gislason GH, Jensen PF, Berger SM, Christiansen CB, et al. Time elapsed after ischemic stroke and risk of adverse cardiovascular events and mortality following elective noncardiac surgery. JAMA 2014; 312: 269-77.

56. Bijker JB, Gelb AW. Review article: the role of hypotension in perioperative stroke. Can J Anaesth 2013; 60: 159-67.

57. Dunham AM, Grega MA, Brown CH 4th, McKhann GM, Baumgartner WA, Gottesman RF. Perioperative low arterial oxygenation is associated with increased stroke risk in cardiac surgery. Anesth Analg 2017; 125: 38-43.

58. Hajibandeh S, Hajibandeh S, Antoniou SA, Torella F, Antoniou GA. Effect of beta-blockers on perioperative outcomes in vascular and endovascular surgery: a systematic review and meta-analysis. Br J Anaesth 2017; 118: 11-21.

59. POISE Study Group, Devereaux PJ, Yang H, Yusuf S, Guyatt G, Leslie K, et al. Effects of extended-release metoprolol succinate in patients undergoing non-cardiac surgery (POISE trial): a randomised controlled trial. Lancet 2008; 371: 1839-47.

60. National Institute of Neurological Disorders and Stroke rt-PA Stroke Study Group. Tissue plasminogen activator for acute ischemic stroke. N Engl J Med 1995; 333: 1581-7.

61. Voelkel N, Hubert ND, Backhaus R, Haberl RL, Hubert GJ. Thrombolysis in postoperative stroke. Stroke 2017; 48: 3034-9.

62. Hong KS, Ko SB, Lee JS, Yu KH, Rha JH. Endovascular recanalization therapy in acute ischemic stroke: updated meta-analysis of randomized controlled trials. J Stroke 2015; 17: 268-81.

63. Premat K, Clovet O, Frasca Polara G, Shotar E, Bartolini B, Yger M, et al. Mechanical thrombectomy in perioperative strokes: a case-control study. Stroke 2017; 48: 3149-51.

64. Mehta BK, Kamal H, McMurtray A, Shafie M, Li P. Effect of heparin on recanalization in acute stroke patients with intra-arterial thrombi. Neurol Int 2015; 7: 5807.

65. Chung JW, Kim BJ, Han MK, Ko Y, Lee S, Kang K, et al. Impact of guidelines on clinical practice: intravenous heparin use for acute ischemic stroke. Stroke 2016; 47: 1577-83. 